\title{
ICD-11 revision: where are we now? Ontology- driven tools and the web platform
}

\author{
J Rodrigues ${ }^{1,2}$ \\ From 26th Patient Classification Systems International (PCSI) Working Conference \\ Munich, Germany. 15-18 September 2010
}

\section{Introduction}

ICD is the international de facto standard classification for most epidemiological and many health-care and clinical uses. Originally designed to record causes of death, the usage of ICD has been extended to include morbidity classification, reimbursement, and several other specialty areas such as oncology and primary care. The current 10th edition of ICD was endorsed by the World Health Assembly in 1990 and has been periodically updated over the years. Recently, the World Health Assembly decided to develop a completely new version named the 11th revision.

\section{Methods}

In previous revisions of ICD, specialty experts and national representatives of WHO collaborative-classification centers proposed additions and changes to the codes (using lists of codes for creating new drafts). In contrast, the development of ICD-11 aims to create an information infrastructure and workflow processes that utilize knowledge engineering and management techniques that are supported by software. Instead of just codes, titles, and associated rules and indices, the information infrastructure will enable a more detailed definition of disease and health conditions, as well as the use of reference terminologies and ontologies, review of best scientific evidence, and field trials of draft standards.

In terms of workflow, the information infrastructure should support the collaborative development of new content and proposed changes, rigorous review and approval processes, and the creation of draft classifications for field testing. The ICD revision process was initially the work of Topic Advisory Groups (TAG) that had been set up for various specialty areas. The ICD-11 revision process will eventually be opened up for comments and suggestions from interested parties on the Internet.

Lastly, the final output will be multiple for different use cases such as mortality, morbidity and primary care, which can be mapped with ontology-driven tools

\section{Results}

The content model is made up of three different parts:

A) Descriptive Characteristics

ICD Concept Title

Hierarchy, Type and Use

Textual Definition

Terms

Index Terms

Synonyms

Inclusion Terms

Exclusion Terms

B) Clinical Description

Manifestation Properties

Signs \& Symptoms

Findings

Temporal Properties

Severity Properties

Functional Properties

Treatment Properties

Diagnostic Rules

Reason For Encounter

C) Formal Characteristics

Body Structure

Morphologic Abnormality

Causal Properties

Mechanisms/ Agents

Risk Factors

Genomic Characteristics

Dysfunction

${ }^{1}$ SSPIM, CHU Saint etienne, Saint Etienne, France

Full list of author information is available at the end of the article 
The web platform named ICAT has been developed by a team of Stanford University to allow a collaborative population of the content model by their different tags.

The ICD-11 content model is still evolving, but the main components have been specified. A detailed guide describes the expected content and usage of each component. It is the document that records the shared understanding of the content model.

The OWL content model realizes the informal description in the guide and formalizes the three-layer conceptualization of the original UML model.

\section{Conclusions}

The ICD-11 content model is very much a work in progress. Consensus formulation of several components such as temporal properties, severity properties, and diagnostic criteria is not yet available. From the view point of case mix, the new tools will provide an ICD of better quality for morbidity, thus allowing better mapping between diagnosis systems and, as a result of this, better mapping across case-mix systems based on diagnosis coding.

\section{Author details}

${ }^{1}$ SSPIM, CHU Saint etienne, Saint Etienne, France. ${ }^{2}$ WHO FIC Collaborative Centre, WHO FIC Collaborative Centre, Paris, France.

Published: 6 October 2010

doi:10.1186/1472-6963-10-S2-A7

Cite this article as: Rodrigues: ICD-11 revision: where are we now?

Ontology-driven tools and the web platform. BMC Health Services

Research 2010 10(Suppl 2):A7.
Submit your next manuscript to BioMed Central and take full advantage of:

- Convenient online submission

- Thorough peer review

- No space constraints or color figure charges

- Immediate publication on acceptance

- Inclusion in PubMed, CAS, Scopus and Google Scholar

- Research which is freely available for redistribution

Submit your manuscript at www.biomedcentral.com/submit 